\title{
Erratum to: Adjustable Gastric Banding and Sleeve Gastrectomy in Bardet-Biedl Syndrome
}

\author{
S. Mujahid • M. S. B. Huda • P. Beales • P. V. Carroll • \\ B. M. McGowan
}

Published online: 9 January 2015

(C) Springer Science+Business Media New York 2015

\section{OBES SURG (2014) 24:1746-1748}

\section{DOI 10.1007/s11695-014-1379-7}

The published list of references was incomplete. The complete list follows:

1. Beales PL. New criteria for improved diagnosis of Bardet-Biedl syndrome: results of a population survey. Journal of Medical Genetics. 36:437-446. 1999 Jun 1.

2. Klein D. The syndrome of Laurence-Moon-BardetBiedl and allied diseases in Switzerland: clinical, genetic and epidemiological studies. Journal of the Neurological Sciences 1969;9(3):479-513

3. Bardet-Biedl Syndrome. 2003 Jul 14 [Updated 2014 Feb 20]. In: Pagon RA, Adam MP, Ardinger HH, et al., editors. GeneReviews ${ }^{\circledR}$ [Internet]. Seattle (WA): University of Washington, Seattle; 1993-2014. Available from: http://www.ncbi.nlm.nih.gov/books/NBK1363/

4. Stoetzel C, Muller J, Laurier V, et al. Identification of a novel BBS gene (BBS12) highlights the major role of a

The online version of the original article can be found at http://dx.doi.org/ 10.1007/s11695-014-1379-7.

S. Mujahid · M. S. B. Huda $(\varangle) \cdot$ P. V. Carroll • B. M. McGowan Department of Diabetes and Endocrinology, Guy's and St Thomas' NHS Foundation Trust, London, UK

e-mail: bobby.huda@bartshealth.nhs.uk

\section{P. Beales}

Department of Genetics, Guy's and St Thomas' NHS Foundation

Trust, London, UK vertebrate-specific branch of chaperonin-related proteins in Bardet-Biedl syndrome. Am J Hum Genet. 2007;80(1):1-11. DOI:10.1086/510256

5. Green JS. The cardinal manifestations of Bardet-Biedl syndrome, a form of Laurence-Moon-Biedl syndrome. New England Journal of Medicine 1989 Oct 12;321(15):1002-9.

6. Sjostrom CD. Effects of bariatric surgery on mortality in Swedish obese subjects. New England Journal of Medicine 2007 Aug 23;357(8):741-52

7. Daskalakis M. Roux-en-Y gastric bypass in an adolescent patient with Bardet-Biedl syndrome, a monogenic obesity disorder. Obesity Surgery 2010 Jan;20(1):121-5.

8. Beales PL, Elcioglu N, Woolf AS, et al. New criteria for improved diagnosis of Bardet-Biedl syndrome: results of a population survey. J Med Genet. 1999;36(6):437-46.

9. Iannello S. A review of the literature of Bardet-Biedl disease and report of three cases associated with metabolic syndrome and diagnosed after the age of fifty. Obesity Reviews 2002 May;3(2):123-35

10. Imhoff $\mathrm{O}$. Bardet-Biedl syndrome: a study of the renal and cardiovascular phenotypes in a French cohort. Clinical Journal of the American Society of Nephrology 2011 Jan;6(1):22-9

11. Moore SJ, Green JS, Fan Y, et al. Clinical and genetic epidemiology of Bardet-Biedl syndrome in Newfoundland: a 22-year prospective, population-based, cohort study. Am J Med Genet. 2005;132A(4):352-60. DOI:10.1002/ajmg.a.30406 